\title{
A Microextracção em fase sólida como técnica de preparação de amostras para cromatografia
}

\author{
ANA LUÍSA SIMPLÍCIO1,2, LUÍS VILAS BOAS3,4
}

\begin{abstract}
Com este trabalho pretende-se fazer a divulgacão da

microextracção em fase sólida, que é uma técnica que permite fazer pré concentração de compostos para análise por cromatografia em fase gasosa e em fase líquida, sem que seja necessário recorrer ao uso de solventes orgânicos. A técnica tem sido usada principalmente para análise de resíduos de pesticidas em águas, mas actualmente surgem cada vez mais outros tipos de aplicaçôes.
\end{abstract}

\section{INTRODUÇÃO}

A análise de compostos orgâni$\cos$ (componentes ou contaminantes) em amostras ambientais ou de produtos agroalimentares exige normalmente múltiplos passos de processamento com um elevado consumo de solventes orgânicos [1,2]. Essas análises são, por isso, morosas e estão sujeitas a numerosas interferências [3].

A microextracção em fase sólida [4] (MEFS) é uma técnica recente de extraç̧ão e pré-concentração de compostos orgânicos a partir de amostras de ar, água, produtos agroalimentares e fluidos biológicos (sangue, urina, soro), em que não é necessária a utilização de solventes orgânicos.

A amostra é mantida em contacto com uma fibra revestida de um material adsorvente durante o intervalo de tempo suficiente para reter os compostos que vão ser analisados. A fibra é depois introduzida no injector de um cromatógrafo de fase gasosa onde se dá a dessorção térmica. Encontram-se também já descrições da associação da microextracção em fase sólida à cromatografia em fase líquida.

O tempo global da análise é significativamente menor que no caso dos métodos que fazem uso da extracção líquido-líquido ou de outros processos de extracção sólido-líquido. A manipulação da amostra tam- bém é menor pelo que se reduz a probabilidade de contaminações cruzadas ou perca de componentes.

A técnica é potencialmente interessante para aplicação na análise de resíduos de pesticidas em amostras ambientais e na caracterização de aromas em produtos agroalimentares.

O processo de extracção é, no entanto, sensível a interferêncas da matriz o que limita a aplicação do método a amostras relativamente "limpas".

\section{HISTÓRIA}

Aparentemente, a microextracção em fase sólida surgiu da tentativa de Pawliszyn, em 1987, desenvolver um novo sistema de injecção em cromatografia em fase gasosa, que reduzisse os problemas de resolução de picos de compostos de baixa volatilidade $[5,6]$.

Os primeiros dispositivos de microextracção em fase sólida [5] (1990) foram construídos artesanalmente por substituição do filamento de uma seringa Hamilton 7000 por uma fibra óptica não revestida ou revestida com poliimida. Em 1992 a Varian associou-se aos inventores do sistema na tentativa de automatizar o método por adaptação das seringas Hamilton modificadas aos injectores automáticos dos seus cromatógrafos [7].

Em 1993 surgiram os primeiros artigos em que se faz referência à utilização de outros tipos de revestimento [8] e à análise de espaço de cabeça ("headspace") [9]. Só a partir de 1994, com o aparecimento dos primeiros dispositivos não artesanais de MEFS [9], comercializados pela Supelco, é que outros grupos [10-15] que não o de Pawliszyn começaram a utilizar a microextracção em fase sólida. Em 1995 Pawliszyn associou a ténica de MEFS à cromatografia em fase líquida [16], desenvolvendo uma interface que passou a ser comercializada pela Supelco [17] em 1996. Neste ano já numerosos grupos aplicavam a microextracção a diferentes matrizes e compostos.

\section{TEORIA}

O principio da MEFS é a partição do composto a analisar entre a matriz e o meio de extracção [9]. Usando um revestimento polimérico, a quantidade de composto adsorvida pelo revestimento no equilibrio está directamente relacionada com a sua concentração na amostra [18]:

$$
n=\frac{K_{f s} V_{f} C_{0} V_{s}}{K_{f s} V_{f}+V_{s}}
$$

onde $n$ é a massa do composto absorvida, Vs e $V f$ são os volumes da amostra e do revestimento, $K f$ s é o coeficiente de partição do composto entre o revestimento e a amostra e Co é a sua concentração inicial.

Se o volume de amostra fôr significativamente superior ao volume do revestimento, então a expressão pode simplificar-se para:

$$
n=K_{f s} V_{f} C_{0}
$$

Se o revestimento tiver uma grande afinidade ( $K f s$ elevado) então a MEFS tem grande capacidade de concentrar o composto conduzindo a uma boa sensibilidade.

A velocidade da extracção é controlada pelo transporte de massa dos compostos a analisar da amostra para o revestimento e depende do movimento convectivo no ar ou líquido em análise, da velocidade de dessorção de superfícies sólidas (quando presentes) e da velocidade de difusão no revestimento. Numa análise directa numa solução sem partículas em suspensão, o passo limitante será apenas a difusão no revestimento, desde que a amostra seja perfeitamente agitada.

A adsorção é afectada por numerosos factores incluindo o tamanho da molécula, a sua polaridade e a polaridade da matriz, a solubilidade e o pH [14]. Para fenómenos de adsorção e no caso de moléculas com estruturas semelhantes, em geral, quanto maior for a molécula mais fortemente é adsorvida. Esta situação 
que é verificada por exemplo para as $\gamma$-lactonas com uma fibra apolar [14], também pode ser explicada em termos do decréscimo da polaridade com o tamanho da cadeia.

O efeito da polaridade também se observa nas adsorções relativas de álcoois e ésteres, em que se verifica que a derivatização de álcoois a ésteres, com consequente diminuição da polaridade, conduz a um aumento da adsorção [14].

Em fibras de revestimento apolar como polidimetilsiloxano, os ácidos são fracamente adsorvidos [13]. Isto acontece porque a forma iónica do ácido é demasiado hidrofílica para ser adsorvida na superficie hidrofóbica da fibra; como a razão de concentrações da forma iónica e da forma neutra do ácido é dependente do $\mathrm{pH}$ do meio, a adsorção do ácido que só pode ser feita na forma neutra, também depende do $\mathrm{pH}$.

Para que uma molécula seja adsorvida, ela tem que ser dessolvatada primeiro. A entalpia global do processo é a diferença entre a entalpia de adsorção e a entalpia de solvatação. Sendo assim o processo é tanto mais favorável quanto menor for a entalpia de solvatação ou seja quanto menos solúvel na matriz for o composto [14].

\section{APLICAÇÕES DESCRITAS}

Em amostras ambientais (ar, água, águas residuais) têm sido relatados resultados de análise de poluentes como resíduos de pesticidas $[10,18]$, PHAs [4], BTX $[7,4]$, organometálicos voláteis [11], ácidos gordos [20], fenois $[8,18,19]$, etc. Os limites de detecção típicos são inferiores a 1 ppb para muitos compostos [18], nomeadamente variam entre 10 ppt e 1.6 ppb para os fenóis [8] e são inferiores a $50 \mathrm{ppt}$ para vários pesticidas organofosforados [10, 15]. Para ácidos gordos, os limites de detecção referidos variam entre $20 \mathrm{ppt}$ e 760 ppb e diminuem com o aumento da cadeia apolar do ácido [20]; os desvios padrão relativos são quase sempre inferiores a $5 \%$.
Encontram-se também referências à possibilidade de aplicação do método directamente no campo, em que a fibra é exposta ao ar ou água e depois transportada para o laboratório. Em produtos agroalimentares são poucas as aplicações descritas da MEFS para análise de resíduos de pesticidas $[21,22]$; limites de detecção típicos para pesticidas organofosforados são da ordem das 50 ppt em sumo de maçã [21] e da ordem das 5 ppb em néctares de frutos e sumos de frutos não clarificados [22]; as percentagens de recuperação nestas matrizes são da ordem de $70-110 \%$.

Em produtos agroalimentares a MEFS tem sido usada fundamentalmente para caracterização de aromas $[13,14]$ com vista à classificação de variedades de tabaco [23], ervas aromáticas [24], bebidas alcoólicas [12,25], especiarias [26], cafés e sumos de frutos [13].

Em fluidos biológicos têm-se tentado quantificar resíduos de pesticidas mas os resultados apresentam percentagens de recuperação baixas [27]. O método também já foi aplicado na pesquisa de anfetaminas em urina [23] e medicamentos antidepressivos no soro [28].

Encontram-se ainda descrições da aplicação da MEFS na pesquisa de combustiveis líquidos em investigação de fogos $[29,30]$.

\section{PROCESSO EXPERIMENTAL}

Neste método, uma fibra de sílica revestida de um material polimérico adsorvente, é exposta à amostra directamente por imersão (amostras líquidas e gasosas) ou ao espaço de cabeça (todo o tipo de amostras). Segue-se a dessorção dos compostos retidos no injector de um cromatógrafo de fase gasosa por acção da temperatura, sem a utilização de qualquer solvente orgânico. O método não exije equipamento sofisticado. Na figura pode ver-se a estrutura das seringas de MEFS disponíveis actualmente no mercado.

Caso se pretenda utilizar a cromatografia de fase líquida como técnica de separação dos compostos adsorvidos, a fibra é introduzida numa interface muito simples associada à válvula de seis vias ligada ao cromatógrafo.

A dessorção é feita por contacto da fase móvel [17] (dessorção dinâmica). Em alternativa, caso não se disponha desta interface, a fibra pode ser introduzida num volume pré definido de fase móvel ou outro solvente que é depois injectado na coluna da forma habitual (dessorção estática) [17]. Nestes casos são necessárias fibras de fase ligada que não se degradem com solventes orgânicos.

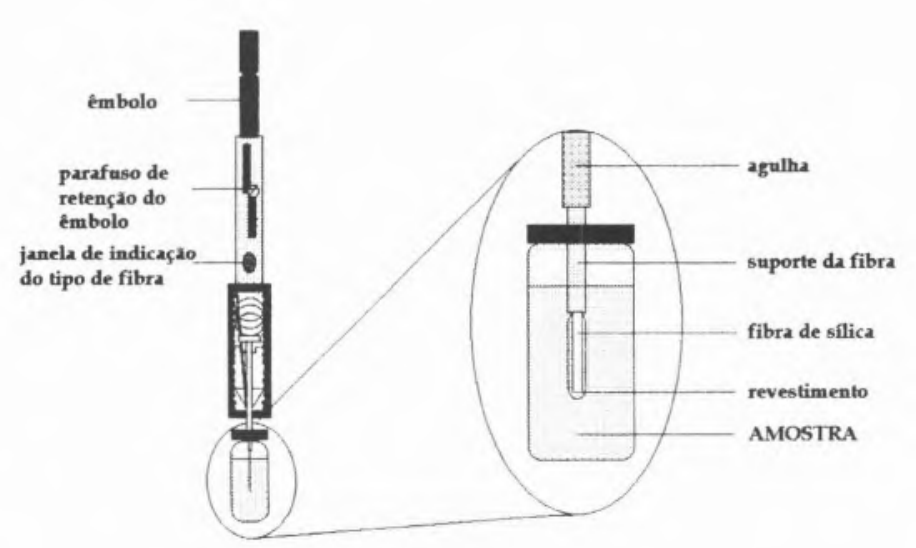

Fig. 1 - Seringa e fibra para MEFS 
Alguns parâmetros podem ser ajustados com vista a optimizar as condições de extraç̧ão por MEFS:

É necessário escolher o tipo de revestimento adequado para a análise em questão. As fibras de MEFS correntemente disponíveis no mercado são revestidas por diferentes espessuras das seguintes fases: poliacrilato (PA), polidimetilsiloxano (PDMS), polidimetilsiloxano/divinilbenzeno (PDMS/DVB), carbowax/divinilbenzeno (CW/DVB) [31] e CarboxenTM/polidimetilsiloxano (CAR/PDMS) [32]. Cada fibra é indicada para grupos de compostos diferentes [31]: a fibra de $100 \mu \mathrm{m}$ de PDMS é a mais adequada para compostos voláteis de baixo peso molecular, enquanto que a de $7 \mu \mathrm{m}$ é mais adequada para semivoláteis (peso molecular um pouco maior). Para compostos polares de matrizes polares, as fibras de PA ou de CW/DVB são mais adequadas, enquanto que a fibra de PDMS/DVB adsorve mais eficientemente compostos voláteis polares pelo que é indicada para álcoois e aminas. Como exemplo, pode citar-se o caso de alguns pesticidas organofosforados como o fosmete e o azinfos-metilo para os quais a fibra de PDMS/DVB tem uma capacidade de concentração cerca de 10 vezes superior à da fibra mais habitualmente usada (PDMS) [21]. A fibra de CAR/PDMS é a mais indicada para a extraç̧ão de moléculas muito pequenas que não são extraídas com a fibra de PDMS como o dióxido de enxofre por exemplo.

Só algumas fibras permitem a imersão em matrizes orgânicas dado que, na maior parte dos casos as fases são não ligadas.

O tempo de exposição da fibra à amostra deve ser suficiente para que uma quantidade significativa dos compostos em análise seja adsorvida. Idealmente nesse intervalo de tempo deve atingir-se o equilíbrio na distribuição dos compostos entre a amostra e o revestimento para que o método não seja tão sensível a pequenas variações no tempo de exposição.
O tempo necessário para atingir o equilíbrio pode ser relativamente longo [7], mas pode ser reduzido se se acelerar o processo de difusão na fase líquida por agitação da amostra. Em geral, quanto maior a velocidade de agitação, menor o tempo necessário para adsorver uma maior quantidade de composto [15]. Normalmente, 15 a 30 minutos são suficientes para concentrar na fibra uma massa significativa do composto a analisar [15]. Para velocidades de agitação muito elevadas pode haver no entanto, redução da massa adsorvida [7]. A agitação pode ser feita por ultrasons [33] ou com agitador magnético. Os limites de deteç̧ão e os desvios padrão relativos também meIhoram com a agitação da amostra [15].

O volume de amostra é importante na medida em que a quantidade adsorvida pela fibra é função do volume e das concentrações iniciais. Extracções sucessivas provocam o decréscimo da concentração das soluções analisadas $[7,13]$, principalmente se o volume e as concentrações iniciais forem reduzidas e as constantes de distribuição forem elevadas.

Em geral, a adição de um electrólito pode alterar um processo de adsorção de duas formas [13]: ou por alteração da superfície entre fases ou por decréscimo da solubilidade de compostos hidrofóbicos na fase aquosa. Aumentando a força iónica do meio por adição de sais podem aumentar-se as constantes de distribuição no sentido da adsorção e assim diminuir os limites de detecção. O tempo necessário para atingir o equilíbrio em soluções não agitadas pode aumentar significativamente na medida em que maior quantidade dos compostos será deslocada para a fibra [7].

A temperatura do injector do cromatógrafo de fase gasosa pode influenciar a área dos picos dos compostos em análise [7], mas essa influência dependerá do tipo de compostos. Deverá ser suficientemente elevada para volatilizar os compostos adsorvidos sem os degradar. O tempo que a fibra permanece no injector do cromatógrafo de fase gasosa deve ser suficiente para que a totalidade dos compostos seja dessorvida, ou seja, para que não haja efeitos de memória nas injecções seguintes. Em geral 1 a 2 minutos são suficientes na maior parte das situações.

A elevação da temperatura de exposição desfavorece o processo de adsorção pela fibra e aumenta a solubilidade dos compostos hidrofóbicos na solução. Assim, para temperaturas superiores à temperatura ambiente observa-se em geral o decréscimo da massa adsorvida [7]. Por outro lado, para temperaturas baixas (da ordem dos $5^{\circ} \mathrm{C}$ ) também há diminuição das áreas obtidas em relação às que se obtêm à temperatura ambiente, o que pode ser explicado pelo decréscimo da difusão [7]. Estas observações são no entanto dependentes do tempo de exposição e da agitação da amostra na medida em que, quando há agitação ou para tempos de exposição longos em que se está mais perto do equilíbrio, a sensibilidade a variações na temperatura é menor.

\section{LIMITAÇÕES DO MÉTODO}

Algumas limitações podem ser apontadas à MEFS, nomeadamente, o estado físico da amostra. O método pode ser aplicado directamente a amostras no estado gasoso e a líquidos mas, para amostras no estado sólido só é possível a análise em espaço de cabeça. Outra limitação é a relativamente reduzida especificidade das fibras que leva a que, conjuntamente com os compostos em análise, sejam extraídos outros que podem causar interferência na análise cromatográfica. Usando detectores específicos, é possível de algum modo "filtrar" a interferência se os compostos em análise forem susceptíveis de ser analisados por um detector específico. Como exemplo pode referir-se o caso dos compostos organofosforados que podem ser analisados por um detector sensível ao fósforo, mas no qual os compostos sem fósforo não 
são detectados. Esta é uma das razões por que o método tem sido mais usado em amostras em que a matriz não interfere significativamente como no caso da água.

A presença de compostos não voláteis como óleos e outras moléculas de elevado peso molecular em solução juntamente com os compostos em análise pode interferir na MEFS directa [9]. Esse facto poderá deverse à formação de uma outra fase que compete pelo composto em análise, ou à ligação desses compostos à fibra.

A presença de partículas sólidas em suspensão em soluções líquidas pode também prejudicar a MEFS por impedimento à difusão ou por adsorção dos compostos em análise que vêem assim reduzida a sua concentração livre [22]. No entanto, como a capacidade de extracção das fibras é muito elevada, é possível diluir as amostras de modo a reduzir a concentração de partículas interferentes sem comprometer significativamente a sensibilidade do método [21].

\section{CONCLUSÕES}

A grande vantagem deste método é a sua simplicidade: podem usarse pequenas quantidades de amostra (tipicamente da ordem de $1 \mathrm{a} 10 \mathrm{ml}$ ) e o seu manuseamento é muito reduzido; o processo de extracção é rápido; o equipamento utilizado é reduzido e de custos moderados e a fibras podem ser reutilizadas muitas vezes, ao contrário de extracção em fase sólida em que cada "cartridge" só pode ser usado uma vez; não é necessário utilizar solventes orgânicos que acarretem problemas de toxicidade e dificuldades de eliminação. Assim, numerosas interferências [3] que são habituais com outros métodos de extracção sólido-líquido ou líquido-líquido, e que são em parte oriundas do processo analítico podem ser evitadas. Como exemplos podem referir-se as interferências introduzidas por solventes orgânicos, materiais de vidro e plástico, material de filtração e adsorventes de ex- tracção em fase sólida bem como as contaminações cruzadas e perdas de compostos. A frequência de limpeza do injector do cromatógrafo de fase gasosa também pode ser menor porque apenas os compostos voláteis que dessorvem termicamente da fibra são introduzidos no injector. Por esta razão, também os tempos de vida útil das colunas são maiores.

Para muitos compostos a capacidade de extracção das fibras é elevada permitindo atingir factores de concentração elevados com uma pequena quantidade de amostra. Podem assim atingir-se limites de detecção mais baixos que com outros métodos.

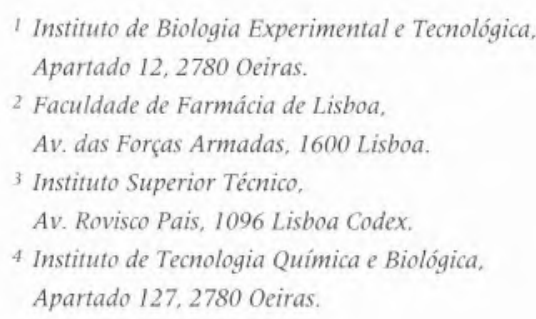

\section{REFERÊNCIAS BIBLIOGRAFICAS}

1. Ed. Hans-Peter Thier \& Hans Zeumer; working group "Analysis", Manual of Pesticide Residue Analysis, vols. 1 \& $2, \mathrm{VCH}, 1987$

2. General Inspectorate for Health Protection, Analytical Methods for Pesticide Residues in Foodstuffs, $6^{\mathrm{a}} \mathrm{ed}$ Min. of Public Health, Welfare and Sport, The Nederlands, 1996.

3. Lino, C.M.; Silveira, M. I. N.; 62, 1996, 19-25

4. Zhang, Z.; Yang, M. J.; Pawlizyn, J.; Anal. Chem., 66 1994, 844A-853A.

5. Pawliszyn, J.; Liu, S.; Analytical Chemistry, 59, 1987 1475-1478.

6. Arthur, C.; Pawliszyn, J.; Analytical Chemistry, 62 1990, 2145 .

7. Arthur, C.L.; Killam L.M.; Buchholz, K.D.; Pawliszyn, J.; Berg, J. R.; Anal. Chem., 64, 1992, 1960-1966.

8. Buchholz, K.; Pawliszyn, J.; Environ. Sci. Technol. 27, 1993, 2844

9. Zhang, Z.; Yang, M. I.; Pawlizyn, I.; Anal. Chem. 65, 1993, 1843-1852
10. Eisert, R.; Levsen K.; Fresenius I. Anal. Chem., 351. 1995, 555-562.

11. Tutschku, S.; Mothes S.; Wennrich, R.; Fresenius I. Anal. Chem., 354, 1996, 587-591.

12. Vas, G.; The Reporter, 15(5), 1996, 6-7.

13. Yang, X.; Peppard, T.; I. Agric. Food Chem., 42 1994, 1925-1930

14. Yang, X.; Peppard T.; LC - GC, 13 (11), 1995, 882 886.

15. Simplício, A. L.; Vilas Boas, L.; 1st European Pesticide Residue Workshop, 1996.

16. Chen, J.; Pawliszyn, J.; Analytical Chemistry, 67 1995, 2530-2533.

17. Shirey, R.; Nolan, L.; Mindrup, R.; The Reporter 15(5), 1996, 8-9.

18. Eisert, R.; Levsen K.; I. Chromatography A 733 , $1996,143-157$

19. Schäfer, B.; Engwald, W.: Fresenius J. Anal Chem.,352, 1995, 535-536.

20. Pan, L.; Adams, M.; Pawliszyn, I.; Anal. Chem., 67, $1995,4396-4403$

21. Simplício, A. L.; Vilas Boas, L.; Actas do $3^{\circ}$ Encontro de Química de Alimentos, 1997, 339.

22. Simplício, A. L.; Vilas Boas, L.; Actas do X Encontro Luso-Galego de Química, Novembro de 1996.

23. Mindrup, R.L.; Supelco-rep., 14 (6), 1995, 1-3.

24. Nunes, V.; Paixão, P.; Pica, C.; Martins, A.; Dias, A.; Vilas Boas, L.; Actas do $3^{\circ}$ Encontro de Química de Alimentos, 1997, 416

25. Lay-Keow Ng; Hupé, M.:Harnois, I.; Moccia, D.; I: Sci. Food Agric, 70, 1996, 380-388.

26. Miller, K.G.; Poole, C.F.:Pawlowski, Chromatographia, 42 (11/12), 1996

27. Lee, X.P.; Kumazawa, T.; Sato, K.; Suzuki, O.; Chromatographia, 42 (3-4), 1996, 135-140.

28. G. Gora-Maslak; The Reporter, 15 (6), 1996 $1-2$.

29. Furton, K.G.; Almirall, J.R.; Bruna, J.C.; I. of Forensic Science, 41(1), 1996, 12-22.

30. Steffen, A.; Pawlizyn, I.; Anal. Commun., 33(4), 1996, 129-131.

31. Chromatography products, Supelco catalog 1996 373-375.

32. Shirey, R.: The Reporter, 16 (1), 1997, 7 .

33. Motlagh, S.; Pawliszyn, 1.; Analytica Chimica Acta 284, 1993, 265-273. 